Aleksandar Miltenović

Milan Banić

https://doi.org/10.21278/TOF.44106

ISSN 1333-1124

eISSN 1849-1391

\title{
THERMAL ANALYSIS OF A CROSSED HELICAL GEARBOX USING FEM
}

\begin{abstract}
Summary
Overheating of gearboxes with crossed axes, such as crossed helical gearboxes, is one of the greatest disadvantages of these gearboxes in comparison with other drives, such as gearboxes with bevel or cylindrical gears. High friction results in the overheating of the transmission and the occurrence of scuffing. The main cause of the overheating is the generation of heat inside the gearbox due to bearing friction, sealing friction and above all, friction between tooth flanks during engagement. By applying the finite element method, thermal stability of a gearbox was predicted, and this procedure was verified on the case of a crossed helical gearbox with an axial distance of $30 \mathrm{~mm}$. Based on the performed numerical investigation, a new procedure for the prediction of heat generation in the crossed helical gear transmission was proposed.
\end{abstract}

Key words: $\quad$ temperature distribution, gearbox, FEM

\section{Introduction}

Overheating is a major problem with gear sets with crossed axes, such as crossed helical gears or worm gears. The main heating source of these gear sets is the contact between tooth flanks. The contact geometry is complicated, resulting in high friction generated between tooth flanks during engagement. High friction leads to overheating that has bad consequences such as:

- Higher power loss. Efficiency is a very important characteristic and crossed helical gear sets have lower efficiency in comparison with cylindrical and bevel gear sets.

- Increased oil temperature and lower oil viscosity can lead to the oil film breakdown and scuffing. Scuffing is very dangerous for gear sets because it can damage gears in a very short period. Scuffing occurrence can be minimized by using a combination of gear set material that has higher scuffing resistance or by using oils of high quality. For example, the maximum operating temperature of mineral oils is $90{ }^{\circ} \mathrm{C}$, and in synthetic oils with additives this temperature can go up to $160{ }^{\circ} \mathrm{C}$. This does not mean that scuffing will not occur at these temperatures, but scuffing resistance will be higher in oils that have higher maximum operating temperatures.

Other heating sources are bearings and sealings, but oil viscosity also affects oil temperature. Higher base oil viscosity leads to a higher oil temperature. All this leads to the conclusion that the thermal design of gearboxes is complicated and it is influenced by a lot of factors. 
Since the scuffing phenomenon primarily depends on the temperature that originated in the zone of contact between gear flanks, a number of studies dealt with the lubricated contact $[1,2]$. This led to the extension of the elastohydrodynamic lubrication theory to the thermal elastohydrohynamic lubrication (TEHL) by including a temperature rise in the contact zone [3].

Thanks to the advances in computational techniques and resources, researchers have been using modelling and simulation of fluid flow in gearbox systems using computational fluid dynamics (CFD) [4] as well as the finite element analysis method. Pakhaliuk [5] calculated the overall wear of a spherical joint by simulating the linear and the volumetric wear according to Archard's law and the mathematical wear model.

Bauer [6] simulated thermal behaviour of a transmission using CFD with good accuracy considering the oil distribution inside and the air flow around the gearbox.

Yazdani developed a modelling methodology for predicting the time-dependent thermofluid state of a gearbox system and he presented this methodology on a set of three interlocking gears that served as a validation vehicle. [7]

Wang [8] investigated meshing friction heat generation and transient thermal characteristics of spiral bevel gears using FEM. He simulated friction heat generation on a real geometry simulating real operating conditions and tried to understand the meshing friction heat generation of a spiral bevel gear as well as to establish a connection between FEM results, damage forms and efficiency.

The novelty of this paper is a fast procedure for estimating the gearbox temperature by using FEM. Gearbox designers often have a task to calculate temperatures of a gearbox in order to determine thermal stability. The procedure that is presented in this paper gives an opportunity to gearbox designers to use a fast FEM calculation of temperatures and a possibility to implement gearbox changes that are not included in standard equations. The oil churring power losses are not considered in the paper.

\section{Test conditions}

The experiments were carried out on a simple gearbox, made for the experimental purpose with a centre-to-centre distance of $30 \mathrm{~mm}$.

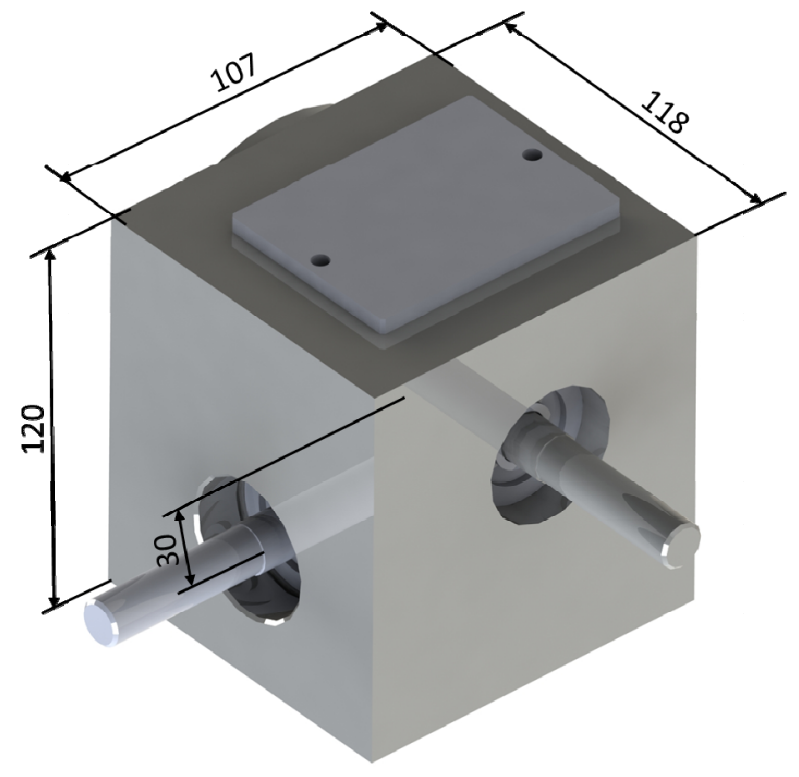

Fig. 1 Test gearbox dimensions 
An asynchronous motor was mounted on the side of the test bench with a worm shaft and a magnetic particle brake was mounted on the side with a gear shaft. The temperature was measured in the gearbox under the gearing of the worm shaft as well as on the worm shaft outside the gearbox. The dimensions of the test bench are shown in Fig. 1 and the parameters are given in Table 1. [9]

Table 1 Data of the test gear pair

\begin{tabular}{|l|c|}
\hline Parameters & Data \\
\hline Centre distance & $30 \mathrm{~mm}$ \\
\hline Module & $1.25 \mathrm{~mm}$ \\
\hline Transmission ratio & 40 \\
\hline Pressure angle & $20^{\circ}$ \\
\hline Wheel material & CuSn12Ni2-C-GCB \\
\hline Worm material & $16 \mathrm{MnCr} 5$ \\
\hline Worm type & ZI \\
\hline Speed & 1500 and 5000 min \\
\hline Torque & $12-32 \mathrm{Nm}$ \\
\hline Lubrication & Oil: Klüber GH6 1500 \\
\hline Housing & Aluminum \\
\hline
\end{tabular}

In the experiments, the oil Klübersynth GH6 -1500 was used. Klübersynth GH6 is synthetic oil with a polyglycol base and additives and it is suitable for use in high performance gears, such as worm gears. It has great scuffing load capacity (API GL-5) and good wear resistance. This oil has relatively good viscosity-temperature behaviour (Table 2). In the experiments, oil with relatively high kinematic oil viscosity $\left(1500 \mathrm{~mm}^{2} / \mathrm{s}\right.$ at $\left.40{ }^{\circ} \mathrm{C}\right)$ was used, while authors tried to minimise wear occurring on the gear tooth flank.

Table 2 Parameters of Klübersynth GH6-1500 oil

\begin{tabular}{|l|c|c|}
\hline Parameters & Unit & GH6-1500 \\
\hline Operating temperature & ${ }^{\circ} \mathrm{C}$ & -20 to 160 \\
\hline Density at $20^{\circ} \mathrm{C}$ & $\mathrm{g} / \mathrm{cm}^{3}$ & 1.08 \\
\hline Kinematic oil viscosity DIN 51562 $\boldsymbol{v}_{\mathbf{4 0}}$ & $\mathrm{mm}^{2} / \mathrm{s}$ & 1500 \\
\hline Kinematic oil viscosity DIN 51562 $\boldsymbol{v}_{\mathbf{1 0 0}}$ & $\mathrm{mm}^{2} / \mathrm{s}$ & 231 \\
\hline
\end{tabular}

\section{Power loss}

Fig. 3 shows the Sankey-diagram for the test bench with all power losses that occurred in the gearbox. The difference between the input and the output power is the sum of power losses. All these power losses were heat sources that increased the temperature of the gearbox.

The sum of power losses $P_{V}$ can be calculated as:

$$
P_{V}=P_{V Z}+P_{V L 1}+P_{V D 1}+P_{V L 2}+P_{V D 2}
$$

where:

$P_{V Z} \quad$ meshing power losses

$P_{V L 1} \quad$ bearing power losses of two bearings on the worm shaft

$P_{V D 1} \quad$ sealing power losses of seals on the worm shaft 
$P_{V L 2} \quad$ bearing power losses of two bearings on the gear shaft

$P_{V D 2} \quad$ sealing power losses of seals on the gear shaft

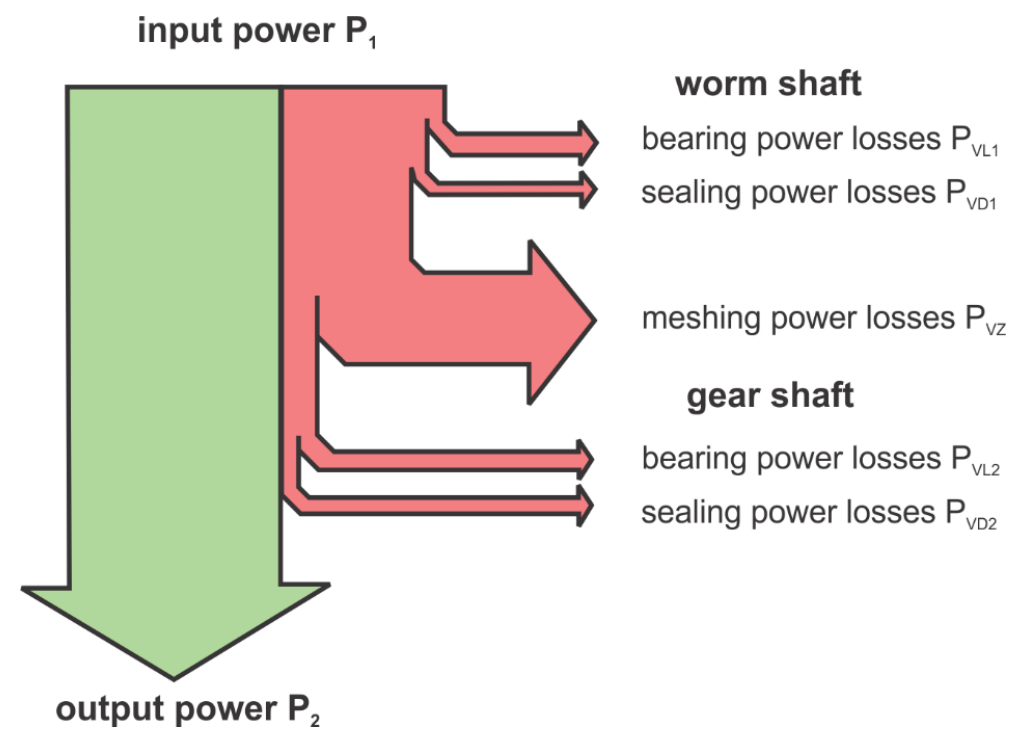

Fig. 2 Sankey-diagram of power flow for a gearbox

The mesh power loss $P_{V Z}$ can be determined according to Equation 2.

$$
P_{V Z}=\left[\frac{1}{\eta_{z}}-1\right] \cdot P_{2 z}=\left[\frac{\tan \left(\beta_{s 2}+\arctan \mu_{z m}\right)}{\tan \beta_{s 2}}-1\right] \cdot P_{2 z}
$$

where:

$$
\begin{array}{ll}
\mu_{z m} & \text { tooth friction coefficient } \\
\beta_{s 2} & \text { helix angle on the gear } \\
P_{2 z} & \text { output power } \\
\eta_{z} & \text { mesh efficiency }\left(\eta_{z}=\frac{\tan \beta_{s 2}}{\tan \left(\beta_{s 2}+\arctan \mu_{z m}\right)}\right)
\end{array}
$$

The tooth friction coefficient depends on the parameters, such as speed, load, centre distance etc. For the crossed helical gears used in the experiment, the calculation of the tooth friction coefficient is given in [10].

Bearing power loss of worm shaft $P_{V L 1}$ and worm shaft $P_{V L 2}$ is the sum of the power losses of all bearings. The power loss of every bearing can be calculated according to SKF calculation [11] by knowing the magnitude of the bearing forces.

The power loss of the bearing can be calculated as:

$$
P_{V L}=1,05 \cdot 10^{-4} \cdot M \cdot n
$$

where:

$\begin{array}{ll}P_{V L} & \text { power loss in } \mathrm{W} \\ M & \text { total friction torque in } \mathrm{Nmm} \\ n & \text { speed in } \mathrm{min}^{-1}\end{array}$

The SKF calculation method [11] gives calculation for real conditions in a bearing and allows further operating conditions to be included in the calculation of the friction torque. 
The total friction torque in the bearing is calculated according to Equation (4):

$$
M=\phi_{i s h} \cdot \phi_{r s} \cdot M_{r r}+M_{s l}+M_{\text {seal }}+M_{d r a g}
$$

where:

$M_{r r} \quad$ rolling friction torque in $\mathrm{Nmm}$

$M_{s l} \quad$ sliding friction torque in $\mathrm{Nmm}$

$M_{\text {seal }} \quad$ friction torque of seal in $\mathrm{Nmm}$

$M_{\text {drag }}$ friction torque due to flow, splash or spray losses in $\mathrm{Nmm}$

$\phi_{i s h} \quad$ oil film thickness factor

$\phi_{r s} \quad$ lubricant displacement factor

Sealing power loss of worm shaft $P_{V D 1}$ and gear shaft $P_{V D 2}$ is the sum of power losses of all sealings. In the gearbox, B2FUD radial shaft seals were used. The sealing power loss of every seal $P_{V D}$ can be calculated according to [11]:

$$
P_{V D}=7.9169 \cdot F_{D, \rho} \cdot\left(\frac{d_{W}}{1000}\right)^{2} \cdot \frac{n}{60}
$$

where:

$F_{D, \rho} \quad$ oil influence factor that depends on oil viscosity

$d_{w} \quad$ diameter of the seal shaft in $\mathrm{mm}$

$n \quad$ speed in $\min ^{-1}$

\section{Experimental results}

The distribution of power losses of the gearbox that are used in the experiment is given in Fig. 3 in percentages for the speed of $5000 \mathrm{~min}^{-1}$. This shows that the highest power losses are in the gearing and that the sum of power losses in the bearing and the sealing is just a half of the mesh power losses.

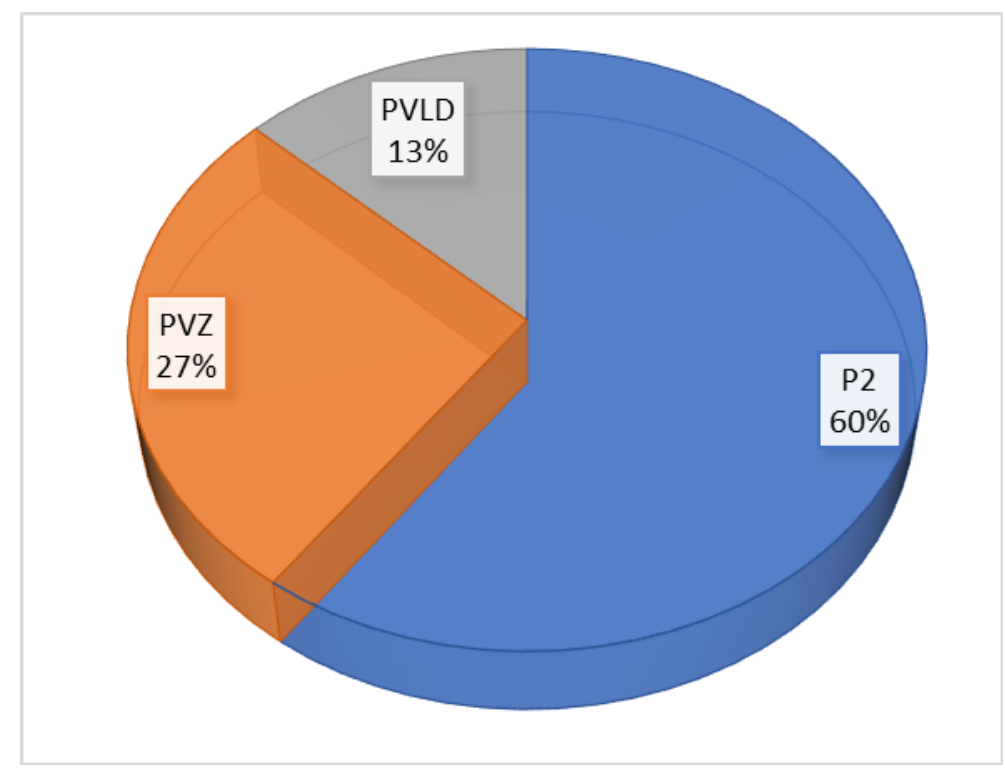

Fig. 3 Distribution of power losses for speed of $5000 \mathrm{~min}^{-1}$ 
The difference between mesh power losses and bearing and sealing power losses is shown in Figure 4. In the case of the speed of $1500 \mathrm{~min}^{-1}$ the mesh power losses are 4 times higher and in the case of the speed of $5000 \mathrm{~min}^{-1}$ the mesh power losses are 2 times higher.

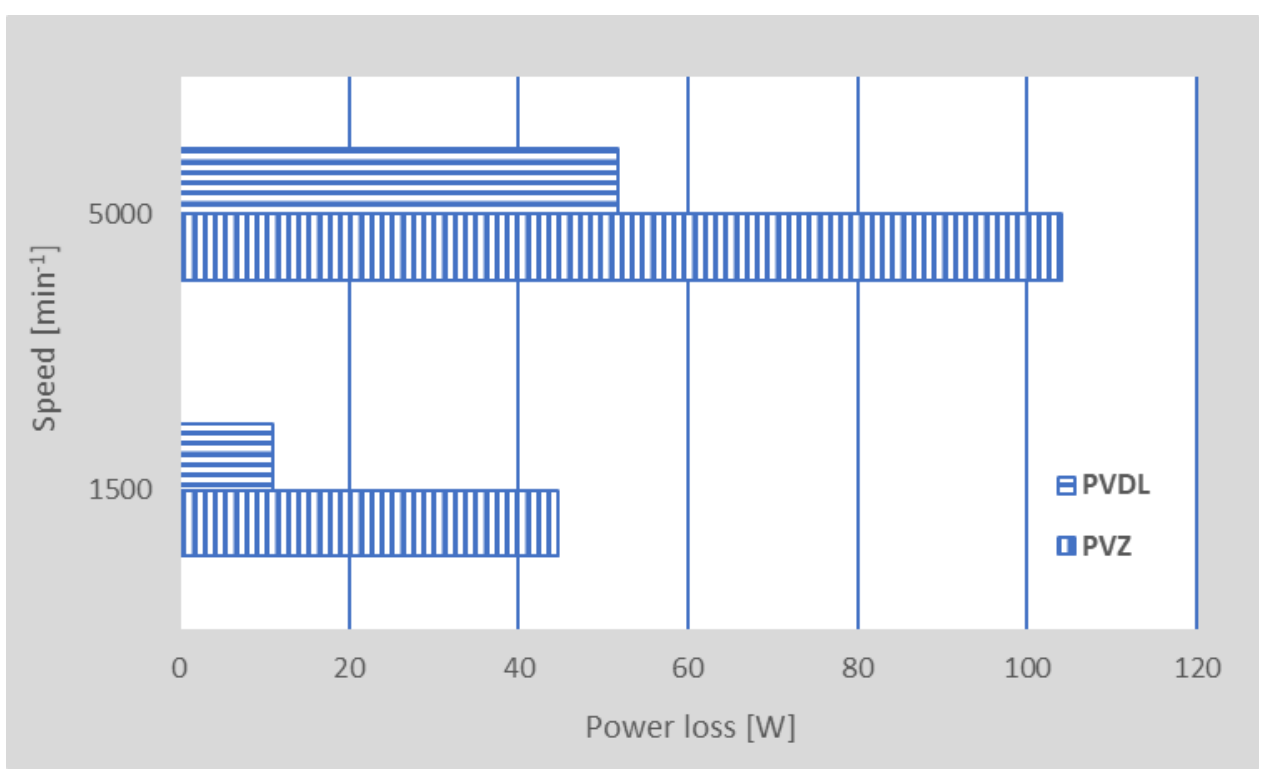

Fig. 4 Difference between mesh power losses and bearing and sealing power losses

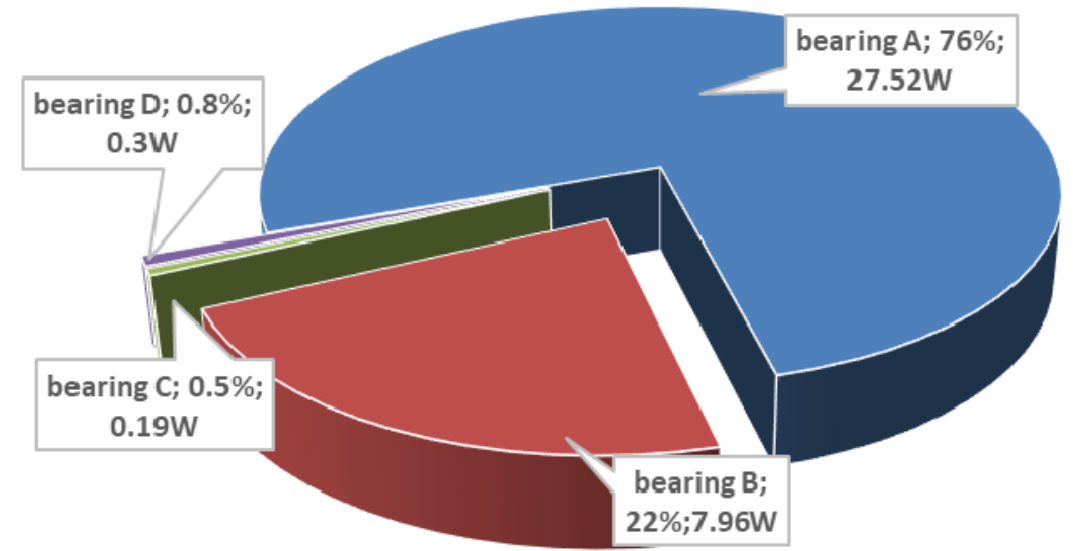

Fig. 5 Distribution of power losses per bearing (average values)

The distribution of bearing power losses of the bearings that were used in the experiment is given in Fig. 5 in a form of average values. Dominant power losses are found in bearing $\mathrm{A}$ and amount to $76 \%$ of all bearing power losses and in bearing $\mathrm{B}$ they amount to $22 \%$ of all bearing power losses. Power losses of bearings $\mathrm{C}$ and $\mathrm{D}$ that are found on the gear shaft and are much lower because the shaft speed is 40 times lower (case 1: $n_{1}=1500 \mathrm{~min}^{-1}$, $n_{2}=37.5 \mathrm{~min}^{-1}$; case $2: n_{1}=5000 \mathrm{~min}^{-1}, n_{2}=125 \mathrm{~min}^{-1}$ ).

\section{Boundary conditions}

In order to define the boundary conditions, in the gearbox analysis it is necessary to examine the heat transfer from all heat sources to the external surface.

Two biggest heat sources in the gearbox are gears (meshing power loss) and bearings (bearing power loss). Gears heat up due to sliding between tooth flanks. One part of heat is transmitted from the gear body on the shaft to the gearbox. Heat is also transmitted to the internal surfaces of the gearbox by oil and air. The accumulated heat of the gearbox is transmitted by convection to the surroundings through the external surface. 
Convection can be approximated as conduction since it has a small influence on heat distribution. In this way, the analysis is reduced to the conductive heat transfer from the source in the gears by oil and air to the gearbox housing, while the heat is transmitted by convection to the surroundings through the external gearbox surface and the shaft. The values of the boundary conditions that are necessary for the FEM analysis are shown in Table 3.

\section{Estimation of temperature using FEM}

The temperature distribution of the crossed helical gearbox is estimated by using FEM and the software ANSYS WORKBENCH. In the simulation, thermal analysis in the time domain is used with a model for thermal transient analysis. Due to the complicated geometry of the crossed helical gear set higher order finite elements SOLID 226 for generating a finite element mesh are used in the analysis.

The crossed helical gear set has a complex temperature distribution during longer operation. The heat generated in the bearings and the gear pair has to be transmitted to the surroundings through the surface of the gearbox without additional cooling. The temperature distribution between the heat source and the surface of the gearbox is determined by convection and conductivity. Heat thermal conductivity $\lambda$ is important for the heat transfer. Heat-transfer coefficient $\alpha$ has to be entered in the simulation in order to take the temperature differences that are a result of conductivity into account. This coefficient depends on a number of parameters, e.g. the used material. Three-dimensional FEM models of a crossed helical gearbox are made so as to determine the temperature distribution and relevant values of the heat transfer coefficient.

The coefficient of the heat transfer to the surroundings based on the data that can be found in literature is $\alpha_{0}=12-15 \mathrm{~W} / \mathrm{m}^{2} \mathrm{~K}[12,13]$ and in the simulation the value of $\alpha_{0}=15 \mathrm{~W} / \mathrm{m}^{2} \mathrm{~K}$ is used. The coefficient of the heat transfer from the rotating shaft to the surroundings based on the data that can be found in literature is $\alpha_{0}=16-80 \mathrm{~W} / \mathrm{m}^{2} \mathrm{~K}$ [14] and in the simulation the value of $\alpha_{\mathrm{o}}=50 \mathrm{~W} / \mathrm{m}^{2} \mathrm{~K}$ is used.

The heat transfer coefficients given in Table 3 are used as an input for the analysis. The power losses are simulated on the surfaces, such as bearing and sealing power losses on those gearbox surfaces that are in contact with bearings and sealings. Meshing power losses are introduced at the contact surfaces between the worm and the gear. In the simulation, the ambient temperature is $25^{\circ} \mathrm{C}$.

Table 3 Values of boundary conditions in the analysis

\begin{tabular}{|l|c|c|}
\hline Parameters & Unit & Value \\
\hline Ambient temperature & ${ }^{\circ} \mathrm{C}$ & 25 \\
\hline Coefficient of heat transfer from gearbox to surroundings $\alpha_{0}$ & $\mathrm{~W} / \mathrm{m}^{2} \mathrm{~K}$ & 15 \\
\hline $\begin{array}{l}\text { Coefficient of heat transfer from shaft to } \\
\text { surroundings } \alpha_{0}\end{array}$ & $\mathrm{~W} / \mathrm{m}^{2} \mathrm{~K}$ & 50 \\
\hline $\begin{array}{l}\text { Coefficient of heat transfer from foundation to surroundings } \\
\alpha_{0}\end{array}$ & $\mathrm{~W} / \mathrm{m}^{2} \mathrm{~K}$ & 10 \\
\hline
\end{tabular}

The FEM model used for the thermal simulation shown in Fig. 7 contains a gear pair, a gearbox, bearings, a wheel shaft, lubricant and air. 


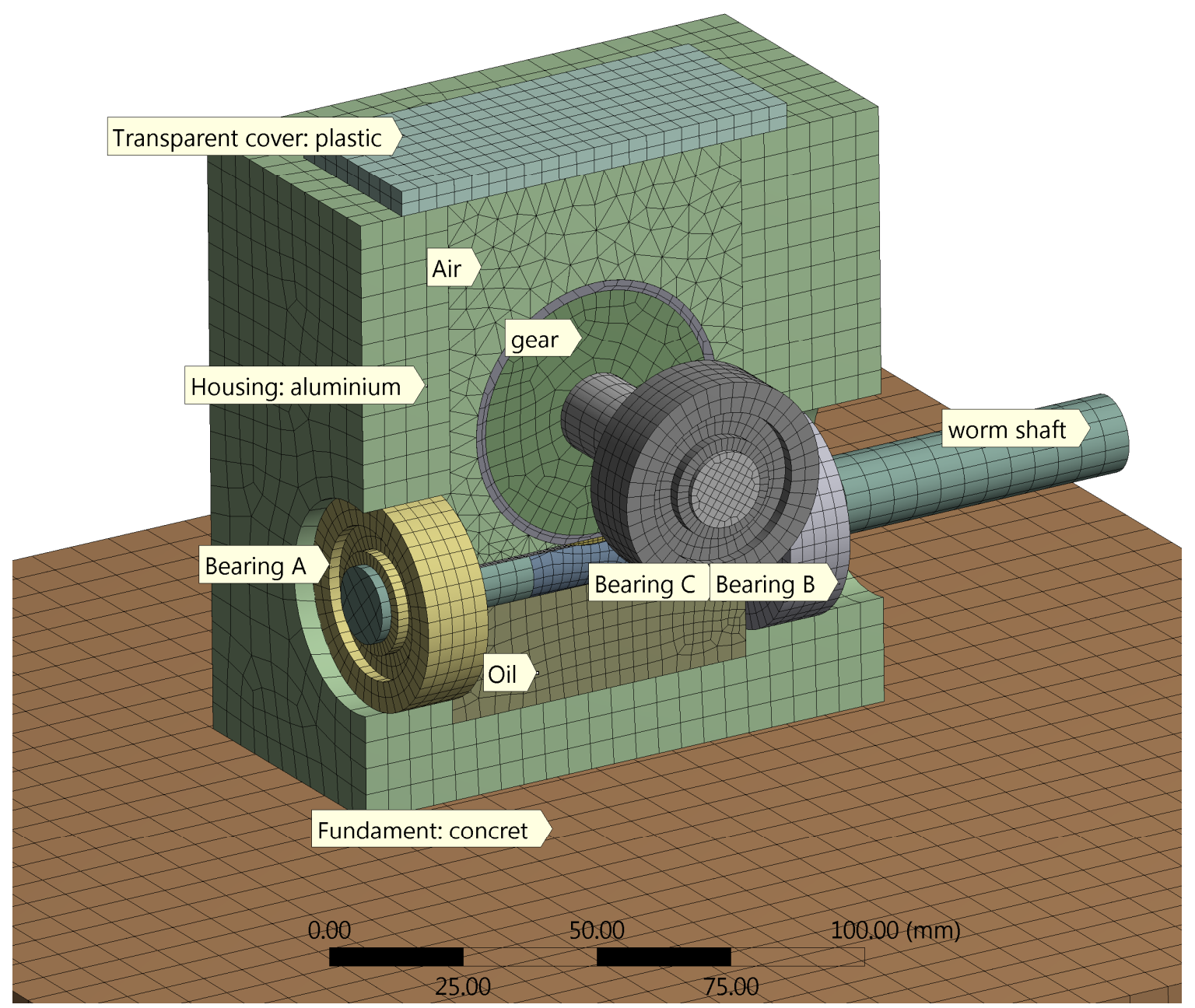

Fig. 6 FEM model of a gearbox

Table 4 Thermal characteristics of used materials

\begin{tabular}{|l|c|c|}
\hline Material & Isotropic thermal conductivity $(\mathrm{W} / \mathrm{mK})$ & Specific heat $(\mathrm{J} / \mathrm{kgK})$ \\
\hline Steel & 46 & 434 \\
\hline Aluminum & 236 & 870 \\
\hline Oil & 0.171 & 2,200 \\
\hline Concrete & 0.72 & 780 \\
\hline Air & 0.0242 & 1,006 \\
\hline Plastic & 0.19 & 1,670 \\
\hline
\end{tabular}

Fig. 8 shows the temperature distribution on the gearbox housing. It can be observed that the temperature on the surface of the gearbox exhibits a very small difference - it is less than one degree.

Fig. 9 shows the temperature distribution in oil used in the gearbox. The experimental oil temperature is measured in the gearbox under the worm. The simulation oil temperature is calculated as an average temperature of the total amount of oil. For example, the average oil temperature in the case of $n_{1}=1500 \mathrm{~min}^{-1}$ and $T_{2}=32 \mathrm{Nm}$ is $t_{\text {avg }}=61.55^{\circ} \mathrm{C}$, while $t_{\max }=76.79^{\circ} \mathrm{C}$ and $t_{\min }=54.85^{\circ} \mathrm{C}$. 


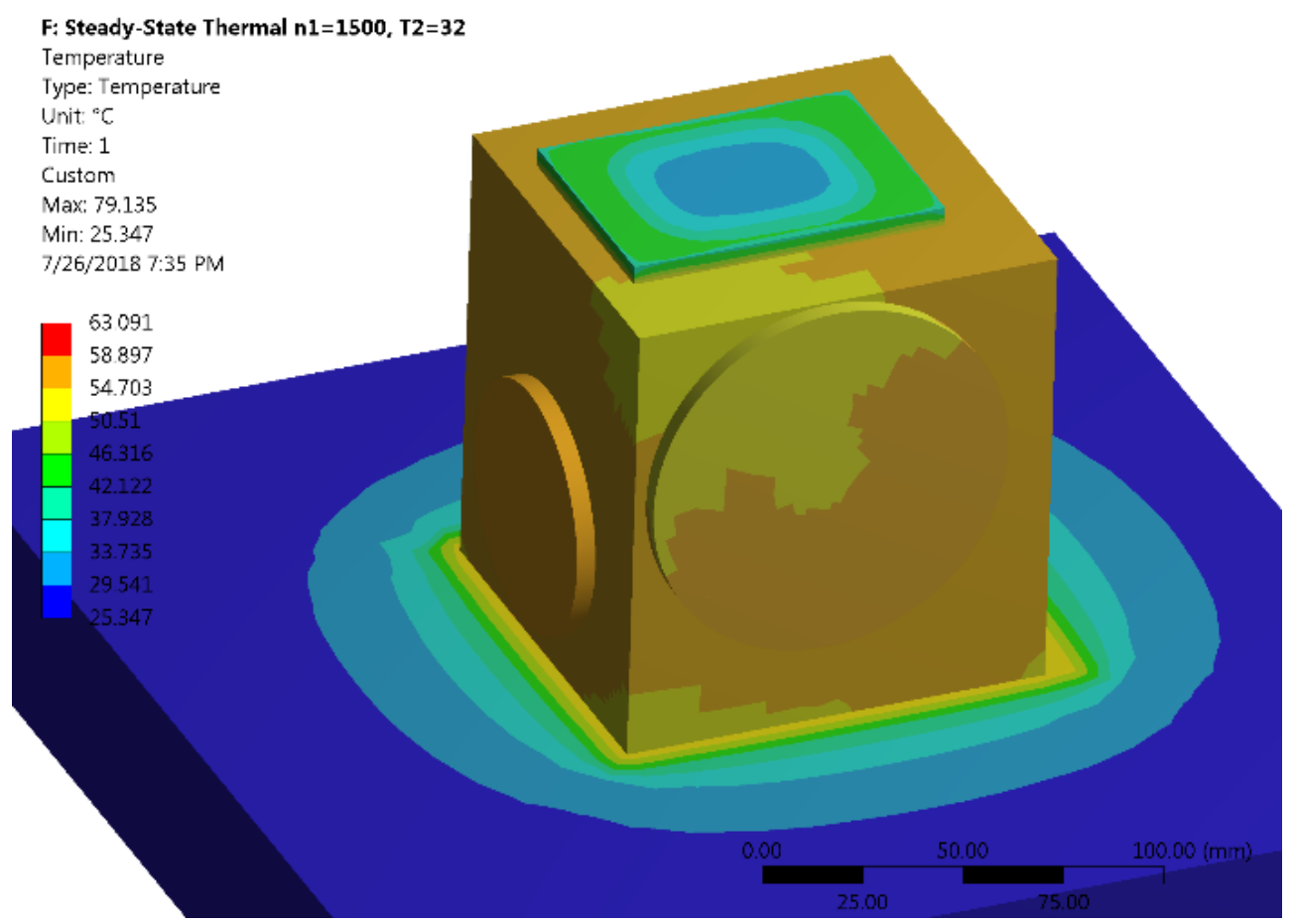

Fig. 7 Distribution of temperature on gearbox housing

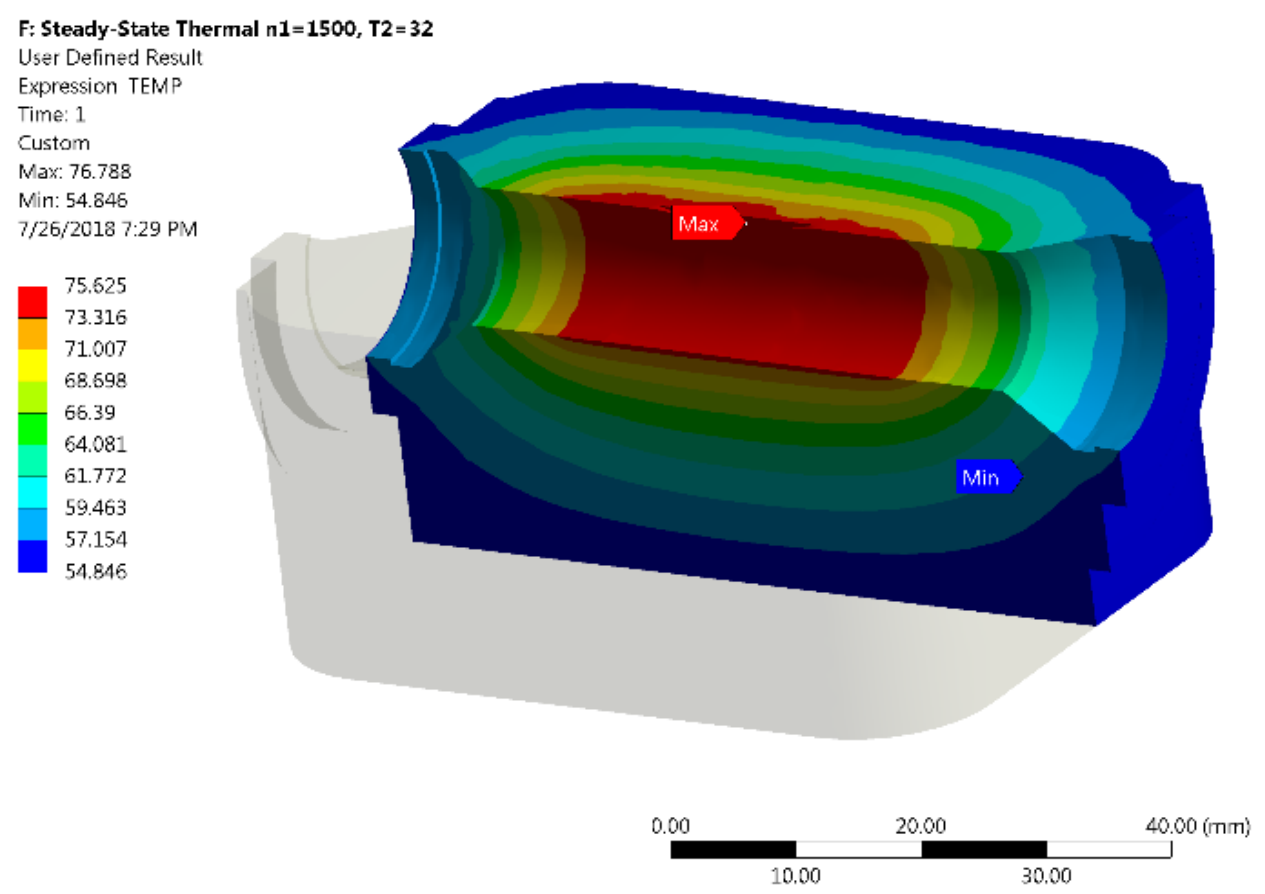

Fig. 8 Distribution of temperature in gearbox oil

Fig. 9 shows a comparison between the experimental and the simulation results for different output torque and speed of $n_{1}=1500 \mathrm{~min}^{-1}$. The simulation results are a little lower than the experimental results, and the average difference is $3.57^{\circ} \mathrm{C}$ or $6.49 \%$. The smallest difference is found for $T_{2}=12 \mathrm{Nm}$ and it is $2.32{ }^{\circ} \mathrm{C}$ or $4.87 \%$. As the output torque grows the difference between the experimental and the simulation results grows also and for $T_{2}=32 \mathrm{Nm}$ it is $4.52{ }^{\circ} \mathrm{C}$ or $7.32 \%$. 


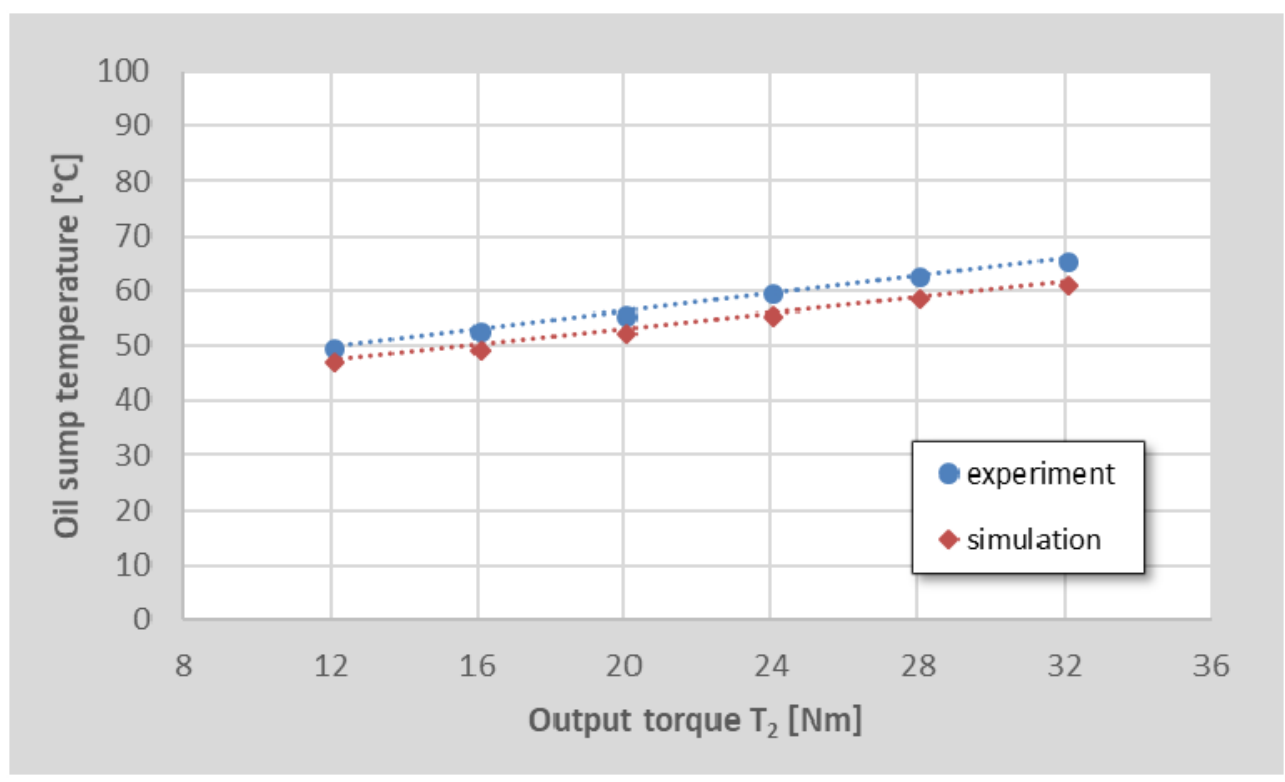

Fig. 9 Comparison of experimental and simulation results for different output torque and speed of $n_{1}=1500 \mathrm{~min}^{-1}$

Fig. 10 shows a comparison of the experimental and the simulation results for different output torque and speed of $n_{l}=5000 \mathrm{~min}^{-1}$. The simulation results are a little lower than the experimental results, and the average difference is $7.09^{\circ} \mathrm{C}$ or $9.61 \%$. The smallest difference is found for $T_{2}=32 \mathrm{Nm}$ and it is $5.92{ }^{\circ} \mathrm{C}$ or $6.93 \%$. As the output torque grows the difference between the experimental and the simulation results decreases and for $T_{2}=12 \mathrm{Nm}$ it is $8.29^{\circ} \mathrm{C}$ or $12.63 \%$.

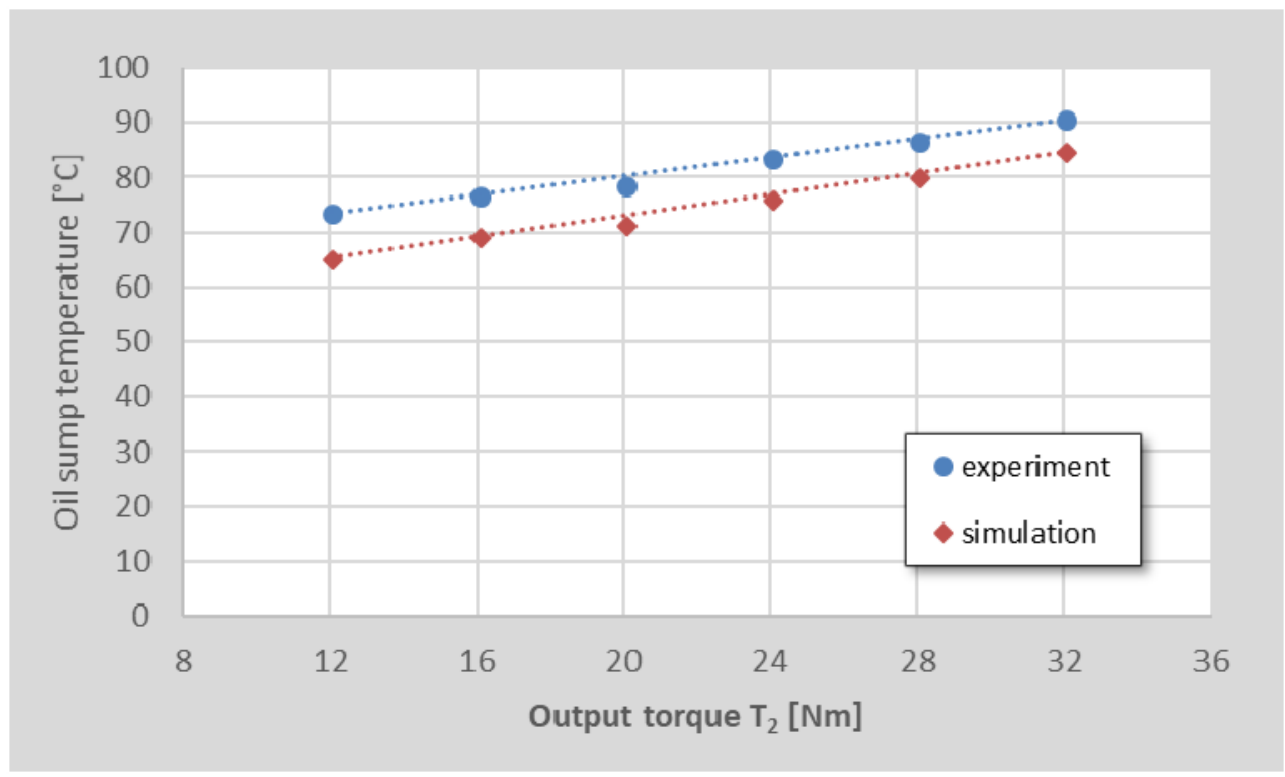

Fig. 10 Comparison of experimental and simulation results for different output torque and speed of $n_{1}=5000 \mathrm{~min}^{-1}$

The smallest difference for all the cases is in the case when $n_{1}=1500 \mathrm{~min}^{-1}$ and $T_{2}=12 \mathrm{Nm}$, while the biggest difference is in the case when $n_{1}=5000 \mathrm{~min}^{-1}$ and $T_{2}=12 \mathrm{Nm}$. In all the cases the simulation temperatures are lower than the experimental temperatures. 


\section{Conclusions}

This paper deals with a fast procedure for the investigation of the gearbox thermal stability by using FEM. This procedure allows gearbox designers to estimate the thermal stability of a gearbox in a relatively short period of time using a simplified geometry and without addressing complex gearbox topics, such as gearing, bearings etc.

The comparison of the results shows that in all the cases the simulation temperatures are lower than the experimental temperatures. In the case when the speed $n_{1}=1500 \mathrm{~min}^{-1}$ the simulation temperatures are lower by $3.57^{\circ} \mathrm{C}$ to $6.49 \%$ and in the case when the speed $n_{1}=5000 \mathrm{~min}^{-1}$ the simulation temperatures are lower by $7.09^{\circ} \mathrm{C}$ to $9.61 \%$.

Differences between the experimental and the simulation temperatures are relatively small as the level of approximations is relatively high, which justified all approximations. This approach provides product developers with a fast procedure for calculating the thermal load capacity of crossed helical gearboxes as well as for investigating how changes in the gearbox structure can influence the gearbox thermal stability.

\section{REFERENCES}

[1] Liou J.J., A theoretical and experimental investigation of roller and gear scuffing (Ph.d. thesis), The Ohio State University, 2010

[2] Proctor M.F., Oswald F.B., Krantz T.L., Shuttle rudder/speed brake power drive unit (pdu) gear scuffing tests with flight gears, NASA Technical Report 2005-214092, 2005

[3] Sadeghi F., Sui P., Thermal elastohydrodynamic lubrication of rolling/sliding contacts, J. Tribol. 1990, 112 (2), 189-195. https://doi.org/10.1115/1.2920241

[4] Hill M., Kunz R.F., Medvitz R.B., Handschuh R.F., Long L.N., Noak R.W., CFD Analysis of Gear Windage Losses: Validation and Parametric Aerodynamic Studies, Journal of Fluids Engineering, 2011 133 (3), pp. 031103-1-031103-10. https://doi.org/10.1115/1.4003681

[5] Pakhaliuk, V., Poliakov, A., Simulation of Wear in a Spherical Joint with a Polymeric Component of the Total Hip Replacement Considering Activities of Daily Living, Facta Universitatis: Mechanical Engineering 2018, 16(1), pp. 51-63. https://doi.org/10.22190/fume171226006p

[6] Bauer, B., Hambrecht, R., Kubo, A., Thermal analysis and optimisation of gearboxes by simulation, International Conference on Gears 2017, VDI-Berichte 2294.2, pp. 917-926

[7] Yazdani M., Soteriou C.M., Sun F., Chaudhry Z., Prediction of the thermo-fluids of gearbox systems, International Journal of Heat and Mass Transfer 2015, 81, pp. 337-346. https://doi.org/10.1016/j.ijheatmasstransfer.2014.10.038

[8] Wang Y., Tang W., Chen Y., Wang T., Li G., Ball D.A., Investigation into the meshing friction heat generation and transient thermal characteristics of spiral bevel gears, Applied Thermal Engineering 2017, 119, pp. 245-253. https://doi.org/10.1016/j.applthermaleng.2017.03.071

[9] Miltenovic, A.: Verschleißtragfähigkeitsberechnung von Schraubradgetrieben mit Schaubrädern aus Sintermetall, Dissertation Ruhr-University Bochum, 2012.

[10] Miltenovic, A., Kuzmanović, S. Miltenović, V., Tica, M., Rackov, M., Thermal Stability of Crossed Helical Gears with Wheels Made from Sintered Steel, Thermal Science 2012, 16(2), pp. 607-619. https://doi.org/10.2298/tsci120503190m

[11] SKF: Hauptkatalog 5000 G. SKF GmbH, Schweinfurt, 2004

[12] Böge, A., Handbuch Maschinenbau: Grundlagen und Anwendungen der Maschinenbau-Technik. Springer Fachmedien Wiesbaden, 2011.

[13] Cerbe, G., Wilhelms, G., Technische Thermodynamik: Theoretische Grundlagen und praktische Anwendungen. Gebundene Ausgabe - Hanser 2010. https://doi.org/10.3139/9783446437500

[14] Marco Pech: Tragfähigkeit und Zahnverformung von Schraubradgetrieben der Werkstoffpaarung Stahl/Kunststoff, Dissertation, RUB, 2012 
Submitted: $\quad 23.01 .2019$

Accepted: $\quad 27.11 .2019$ assis. prof. Aleksandar Miltenović assis. prof. Milan Banić

University of Niš

Faculty of Mechanical Engineering

Aleksandra Medvedeva 14 $18000 \mathrm{Niš}$

Serbia 